\title{
O PROTAGONISMO DO FÓRUM ESTADUAL DE EDUCAÇÃO NA ELABORAÇÃO DO PLANO ESTADUAL DE EDUCAÇÃO DE MATO GROSSO DO SUL
}

\author{
Simone Estigarribia de Lima'
}

Elisangela Alves da Silva Scaff2

\section{RESUMO:}

Constitui objetivo desse texto analisar a atuação do Fórum Estadual de Educação de Mato Grosso do Sul no processo de elaboração do Plano Estadual de Educação. O estudo foi elaborado a partir de metodologia qualitativa, por meio de levantamento e análise de documentos emanados do Fórum Estadual de Educação de Mato Grosso do Sul, como atas, relatórios, documentos orientadores, ofícios, entre outros. Os documentos analisados permitem verificar que o Fórum Estadual de Mato Grosso do Sul se constituiu em um espaço de estudos, debates e sistematização de propostas para o Plano Estadual de Educação 2014-2024. Contudo, esse processo histórico, de conflitos e de consensos, construído por inúmeros sujeitos, não se encerra com sua legitimação legal, uma vez que o planejamento, enquanto política pública, é uma série histórica de ações e intenções de muitos participantes e não se resume a uma Lei ou projeto, mas requer o mesmo entusiasmo participativo nas outras fases dessa política, consubstanciadas nos processos de monitoramento e avaliação do plano aprovado.

Palavras-chave: Planejamento Educacional, Plano Estadual de Educação, Fórum Estadual de Educação.

\section{PROTAGONISM OF THE STATE EDUCATION FORUM IN THE FORMULATION OF THE MATO GROSSO DO SUL STATE EDUCATION PLAN}

\section{ABSTRACT:}

The objective of this text is to analyze the performance of the State Education Forum of Mato Grosso do Sul in the process of elaboration of the State Education Plan. The study was prepared based on a qualitative methodology, through survey and analysis of documents emanating from the State Education Forum of Mato Grosso do Sul, such as minutes, reports, guidance documents, letters, among others. The documents analyzed allow us to verify that the State Forum of Mato Grosso do Sul constituted a space for studies, debates and systematization of proposals for the State Education Plan 2014-2024. However, this historical process of conflict and consensus, built by countless subjects, does not end with its legal legitimacy, since planning, as a public policy, is a historical series of actions and intentions of many

\footnotetext{
1 Doutora em Educação pela Universidade Federal da Grande Dourados (UFGD). Pedagoga no Instituto Federal do Amazonas. São Gabriel da Cachoeira, AM. Brasil. Orcid: https://orcid.org/0000-0002-7091-7549. E-mail: simoneestilima@gmail.com 2 Doutora em Educação pela Universidade de São Paulo (USP). Professora do Programa de Pós-Graduação em Educação da Universidade Federal do Paraná (UFPR). Curitiba, PR. Brasil. Orcid: https://orcid.org/0000-0002-7682-0879. E-mail: elisscaff@gmail.com
} 
participants and is not limited to a law or project, but requires the same participatory enthusiasm in the other phases of that policy, embodied in the monitoring and evaluation processes of the approved plan.

Keywords: Educational Planning, State Education Plan, State Education Forum.

\section{PROTAGONISMO DEL FORO ESTATAL DE EDUCACIÓN SOBRE LA FORMULACIÓN DEL PLAN ESTATAL DE EDUCACIÓN DE MATO GROSSO DO SUL}

\section{RESUMEN:}

El objetivo de este texto es analizar el desempeño del Foro de Educación del Estado de Mato Grosso do Sul en el proceso de elaboración del Plan de Educación del Estado. El estudio se preparó con base en una metodología cualitativa, a través de encuestas y análisis de documentos provenientes del Foro de Educación del Estado de Mato Grosso do Sul, como actas, informes, documentos de orientación, cartas, entre otros. Los documentos analizados nos permiten verificar que el Foro Estatal de Mato Grosso do Sul constituía un espacio para estudios, debates y sistematización de propuestas para el Plan Estatal de Educación 2014-2024. Sin embargo, este proceso historico de conflicto y consenso, construido por innumerables sujetos, no termina con su legitimidad legal, ya que la planificación, como política pública, es una serie historica de acciones e intenciones de muchos participantes y no se limita a una ley o proyecto, pero requiere el mismo entusiasmo participativo en las otras fases de esa política, incorporada en los procesos de monitoreo y evaluación del plan aprobado.

Palabras clave: Planificación educativa, Plan estatal de educación, Foro estatal de educación.

\section{INTRODUÇÃO}

Esse estudo tem com objeto de investigação o Fórum Estadual de Educação de Mato Grosso do Sul, particularmente no que se refere a sua atuação na elaboração do Plano Estadual de Educação, considerando que é uma das suas incumbências estabelecidas pelo Plano Nacional de Educação 2014-202433.

\footnotetext{
3 A investigação aqui apresentada compõe a pesquisa em rede denominada "O planejamento educacional em municípios sul-mato-grossenses: do plano de ações articuladas ao plano municipal de educação", financiada pela Chamada FUNDECT/CAPES $N^{\circ} 11 / 2015$, desenvolvida pelos integrantes da Linha de Pesquisa "Políticas e gestão da educação" do Programa de Pós-Graduação em Educação da Universidade Federal da Grande Dourados (UFGD), em articulação com pesquisadores da Universidade Católica Dom Bosco (UCDB); Universidade Estadual de Mato Grosso do Sul (UEMS); Universidade de Brasília (UnB), Universidade Federal do Espírito Santo (UFES) e Universidade Federal do Paraná (UFPR), cujas pesquisas se articulam pela Rede de Estudos e Pesquisas em Planejamento e Gestão Educacional (REPLAG).
} 
Os Fóruns Permanentes de Educação devem se constituir enquanto espaços de participação da sociedade civil para formulação e acompanhamento da política educacional em cada território, sendo considerados instâncias fundamentais para a materialização do direito constitucional da gestão democrática e reconhecimento da participação social como direito de todos e todas.

A CF de 1988, em seu art. 29, estimula a participação nas tomadas de decisões por meio do princípio da cooperação com movimentos sociais no planejamento municipal. Os art. 194, 198, 204, 206 e 227 ressaltam a participação direta na gestão administrativa da saúde, assistência social, educação (MILANI, 2008).

Gadotti (2014) destaca que as conquistas da participação no planejamento e organização da educação nacional ainda são lentas e pequenas, mas alcançadas com muita luta. Exemplo disso é o Fórum Nacional de Educação, figura instituída no âmbito do Ministério da Educação, reponsável pela articulação e coordenação das conferências nacionais de educação (GANZELI, 2012). Dentre os avanços da CONAE está a criação do FNE que tem a incumbência

[...] convocar e coordenar as próximas edições da Conae; acompanhar a tramitação do novo PNE (2011-2020) no Congresso Nacional; incidir pela implementação das diretrizes e deliberações tomadas nesta e nas demais edições da Conae. Nesse sentido, é importante que seja institucionalizada a prática de conferências municipais e estaduais de educação, com ocorrência de até quatro anos, que deverão preceder as conferências nacionais de educação (BRASIL, 2010a, p. 44-45).

Instâncias privilegiadas de debate e planejamento educacional, os fóruns ganham força com a criação do Fórum Nacional de Educação (FNE) pela Portaria Ministerial $n^{\circ} 1407$, de 14 de dezembro de 2010, que os designa como: 
[...] de caráter permanente, tem como finalidade de coordenar as conferências nacionais de educação, acompanhar e avaliar a implementação de suas deliberações e promover as articulações necessárias entre os correspondentes fóruns de educação dos Estados do Distrito Federal e dos municípios (BRASIL, 2010b).

A partir desta Portaria foram criados Fóruns Permanentes de Educação em todos os estados e no Distrito Federal, cujas Leis de criação, em grande parte, estão disponíveis no portal eletrônico do $\mathrm{FNE}^{4}$, onde é possível acessar os Fóruns Estaduais de cada estado, que apresentam informações sobre a quantidade de municípios que possuem fóruns educacionais, nome da coordenação, alguns documentos, contatos, acompanhamento dos Planos Municipais de educação com ajuda de um mapa.

Embora o portal eletrônico seja bem organizado e apresente riqueza de informações ainda carecem de atualização, uma vez que alguns municípios não disponibilizaram a Lei de criação dos seus Fóruns Estaduais e 12 estados não disponibilizaram seus documentos em seus portais eletrônicos.

Entre os estados que divulgaram seus documentos percebe-se que a maioria dos Fóruns foi criada após 2011, a saber: Acre (2012), Alagoas (2012), Bahia (2012), Ceará (2012), Distrito Federal (2012), Espírito Santo (2011), Maranhão (2011), Paraíba (2011), Paraná (2013) e Pernambuco (2011). Os únicos fóruns criados antes da publicação da portaria são os dos estados de Mato Grosso do Sul (1997) e de Goiás (1998).

Considerando o conceito ampliado de Estado, o Fórum de educação potencialmente desempenha papel importante nas políticas educacionais, pelas inúmeras representações que agrega, desenvolvendo consensos e conquistando espaços. Embora seja uma arena recente, os Fóruns são criados num espaço de disputa de posições que se manifesta por meio das Conferências de Educação.

Em âmbito nacional, a aprovação do Plano Nacional de Educação 2014-2024 vem exigir a instalação do Fórum Nacional de Educação (FNE),

\footnotetext{
${ }_{4}$ http://fne.mec.gov.br/foruns-estaduais
} 
com a prerrogativa de subsidiar a criação dos Fóruns Estaduais de Educação (FEE), os quais, por sua vez, devem realizar o monitoramento das metas do Plano Estadual de Educação e promover a criação dos Fóruns Municipais de Educação (FME).

Esse arranjo complexo de articulação da participação da sociedade com o planejamento educacional pode ser uma estratégia para 0 fortalecimento dessas instâncias, visando à consolidação do Sistema Nacional de Educação, previsto desde a Constituição Federal de 1988 e reafirmado no PNE (2014-2024), mas que até o momento enfrenta resistência devido principalmente ao temor da centralidade do planejamento educacional.

Diante do exposto, constitui objetivo desse texto analisar a atuação do Fórum Estadual de Educação de Mato Grosso do Sul no processo de elaboração do Plano Estadual de Educação. O estudo foi elaborado a partir de metodologia qualitativa, por meio de levantamento e análise de documentos emanados do Fórum Estadual de Educação de Mato Grosso do Sul, como atas, relatórios, documentos orientadores, ofícios, entre outros disponibilizados na página eletrônica do FEE-MS5.

O tratamento do corpus documental dessa pesquisa foi realizado tendo como referência os estudos de Richardson (1999), ao postular a necessidade de desvelar o contexto em que tais documentos foram elaborados. Evangelista (2012) chama a atenção para o fato que os documentos oferecem pistas, sinais, vestígios, mas sua interpretação é tarefa única do pesquisador

[...] encontrar o sentido dos documentos e com eles construir conhecimentos que permitam não apenas o entendimento da fonte, mas dos projetos históricos ali presentes e das perspectivas que - não raro obliteradas no texto -estão em litígio e em disputa pelo conceito, pelo que define o mundo, pelo que constitui a história. Podemos afirmar que trabalhar com documentos significa aceder à história, à consciência do homem e às suas possibilidades de transformação (EVANGELISTA, 2012, p. 7).

\footnotetext{
${ }^{5}$ https://sites.google.com/site/forumeducms/
} 
Nesse sentido, a análise e a interpretação dos documentos vão para além das palavras que o compõem, cada documento é lido e relido dentro do seu contexto de produção, é relacionado com outros documentos de seu contexto articulando níveis macro e micro de análise, sem pretensões generalizantes, uma vez que trata de um contexto local específico.

\section{FÓRUM ESTADUAL DE EDUCAÇÃO DE MATO GROSSO DO SUL (FEEMS): CARACTERIZAÇÃO E FUNCIONAMENTO}

O Fórum Estadual de Educação de Mato Grosso do Sul (FEEMS), caracteriza-se como um órgão permanente de consulta, de assessoramento e de deliberação de propostas para implantação, implementação e avaliação de políticas educacionais, com vistas a possibilitar a interlocução entre sociedade civil e governo (FÓRUM ESTADUAL DE EDUCAÇÃO, s/d).

A criação do FEEMS se deu pelo Conselho Estadual de Educação (CEE) em 7 de novembro de 1997 no II Seminário Estadual sobre a LDB/1996, em parceria com as seguintes instituições: Secretaria de Estado de Educação (SED), Delegacia do MEC em MS (DEMEC), Universidade Federal de MS (UFMS), Universidade Estadual de MS (UEMS), Sindicato dos Estabelecimentos de Ensino de MS (SINEPE), Sindicato dos Trabalhadores das Escolas Particulares de MS, União Nacional de Dirigentes Municipais de Educação de MS (UNDIME), Universidade Católica Dom Bosco (UCDB), Universidade para o Desenvolvimento do Estado e Região do Pantanal (UNIDERP), Federação dos Trabalhadores em Educação de MS (FETEMS), Secretaria Municipal de Educação de Campo Grande (SEMED) e Organização Mundial de Educação Pré-Escolar (OMEP/BR/MS).

O Fórum é composto por 70 entidades representantes de diversos segmentos e possui duas comissões, ambas de caráter permanente e com planos de trabalho e relatórios específicos. A Comissão de Monitoramento e Sistematização é a instância responsável pelo planejamento, orientação e 
acompanhamento das conferências de educação de Mato Grosso do Sul e dos fóruns estadual e municipais de educação.

A Comissão de Mobilização e Divulgação é a instância responsável, pela articulação e mobilização dos órgãos e segmentos do Estado para a realização das conferências estadual e municipais/intermunicipais de educação e para a implementação de seus fóruns, colaborando com suporte técnico e logístico.

Dentre as tarefas realizadas pela comissão, fez contato com os municípios e organizou o levantamento do andamento dos Fóruns Municipais de Educação. A organização das informações foi feita em um quadro onde os municípios indicavam: o nome do município, responsável pela implantação, contatos e observações. Nas observações a Comissão colocava os andamentos de cada município, em alguns casos mensagens de dúvidas dos municípios (FÓRUM ESTADUAL DE EDUCAÇÃO DE MATO GROSSO DO SUL, 2013a).

Além das comissões, O Fórum possui seis Grupos de Trabalho Permanentes, organizados por eixos temáticos, quais sejam: Educação Básica, Educação Superior, Educação a Distância, Educação Profissional, Educação Especial, Educação para a Diversidade. Esses grupos são instâncias de pesquisas, estudos, debates sobre questões educacionais, e de elaboração de propostas para subsidiar as políticas de educação a serem analisadas e votadas pela Plenária. Cada grupo realiza a escolha em plenária de um coordenador e um coordenador adjunto, com mandato de dois anos, sendo possível a recondução.

O Fórum conta também com os grupos de trabalhos temporários, constituídos para trabalhar em determinado tempo com objetivo específico. Exemplo disso foi o Grupo de Trabalho Temporário (GTT) instituído pela Portaria do FEEMS $n^{\circ} 7$, de 7 de dezembro de 2012. A referida Portaria determinou o prazo de 120 dias. Nesse período o Grupo teve por objetivo integrar e articular o planejamento e as ações dos GTPs e das Comissões do FEEMS (FÓRUM ESTADUAL DE EDUCAÇÃO DE MATO GROSSO DO SUL, 2012). 
Na memória de reunião do GTT do dia 26/03/2013 está presente os trabalhos de organização das Conferências, a videoconferência sobre o Sistema de Eventos, ocorrida em 21/02/2013 na UFMS, promovida pelo FNE.

\section{SEMINÁRIO ESTADUAL DE EDUCAÇÃO: CONSTRUINDO COLETIVAMENTE O PEEMS (2014-2024)}

Com a aprovação do PNE 2014-2024 em junho de 2014, estados e municípios foram instados a elaborarem ou adequarem seus Planos aos moldes do PNE no prazo de um ano. Cumpre salientar que antes mesmo da aprovação do PNE, a Secretaria de Estado de Educação de MS, por meio da Resolução P SED n. 948/14, de 11 de abril de 2014, publicada em 14 de abril de 2014 no Diário Oficialb constituiu Comissão Para a Elaboração do Plano Estadual de Educação 2014-2024, respeitando a indicação de suas instituições (MATO GROSSO DO SUL, 2014b).

Essa comissão teve validade até 31 de dezembro de 2014, sinalizando que esse era o prazo máximo para realização dos trabalhos e aprovação do novo PEE-MS. Nesse período, a Comissão recebeu capacitação dos avaliadores estaduais da Secretaria de Articulação com os Sistemas de Ensino - SASE/MEC (FÓRUM ESTADUAL DE MATO GROSSO DO SUL, 2014b)

A comissão foi composta por representantes de 15 instituições do estado, tendo um representante titular e um suplente totalizando 30 componentes, ainda contou com vários colaboradores, na maioria da Secretaria de Educação do Estado. As instituições que integraram a comissão foram: Assembleia Legislativa de MS, Conselho Estadual de Educação de Mato Grosso do Sul (CEE), Centro Universitário Anhanguera UNAES, Federação Estadual dos Trabalhadores em Educação de MS, (FETEMS), Fórum Estadual de Educação de Mato Grosso do Sul (FEEMS), Fundação Universidade Federal da Grande Dourados (UFGD), Instituto Federal de Educação, Ciência e Tecnologia de MS (IFMS), Secretaria de

\footnotetext{
${ }^{6}$ https://www.jusbrasil.com.br/diarios/69039453/doems-14-04-2014-pg-49?ref=next_button
} 
Estado de Educação (SED), Sindicato dos Estabelecimentos de Ensino de MS (SINEPE), Universidade Anhanguera - UNIDERP, União dos Dirigentes Municipais de Educação (UNDIME), União Nacional dos Conselhos Municipais de Educação (UNCME), Universidade Católica Dom Bosco (UCDB), Universidade Federal de Mato Grosso do SUL (UFMS), Universidade Estadual de Mato Grosso do SUl (UEMS) (MATO GROSSO DO SUL, 2014b). Todas as instituições que tiveram representação na Comissão, eram integrantes do FEE-MS. A coordenadora da Comissão além de ter coordenado o II COEED, também era coordenadora do FEE-MS (2012-2016), presidente do CEE-MS e representante da SED no Fórum.

Quadro 1: Instituições /órgãos/segmentos da sociedade integrantes do FEEMS e da Comissão para elaboração do PEE-MS, organizados por quantidade de plenárias que participaram em 2014

\begin{tabular}{|c|c|c|c|c|c|c|c|}
\hline \multirow{2}{*}{$\begin{array}{c}\text { Relação das } \\
\text { instituições/órgãos/segmentos da } \\
\text { sociedade integrantes do FEEMS, } \\
\text { organizados por quantidade de } \\
\text { plenárias que participaram }\end{array}$} & \multirow{2}{*}{$\begin{array}{c}\mathbf{N}^{\circ} \\
\text { integrantes } \\
\text { Comis- } \\
\text { são }\end{array}$} & \multirow{2}{*}{$\begin{array}{c}\mathbf{N}^{\circ} \\
\text { integrantes } \\
\text { Colabo- } \\
\text { radores }\end{array}$} & \multicolumn{5}{|c|}{$\begin{array}{l}N^{\circ} \text { de represen- } \\
\text { tantes registrado } \\
\text { nas atas } 2014\end{array}$} \\
\hline & & & \begin{tabular}{|l|}
11 \\
\end{tabular} & $2^{2}$ & $3^{3}$ & $4^{4}$ & $5^{5}$ \\
\hline $\begin{array}{l}\text { Conselho Estadual de Educação de MS } \\
\text { - CEE/MS }\end{array}$ & 2 & 3 & 2 & 3 & 1 & 4 & 3 \\
\hline $\begin{array}{l}\text { Conselho Municipal de Educação } \\
\text { Campo Grande }\end{array}$ & --- & 1 & & & & & \\
\hline $\begin{array}{l}\text { Fórum Estadual de Educação de Mato } \\
\text { Grosso do Sul FEE-MS }\end{array}$ & 2 & --- & & & & & \\
\hline $\begin{array}{l}\text { Secretaria de Estado de Educação - } \\
\text { SED/MS Campo Grande }\end{array}$ & 2 & 17 & 2 & 6 & 3 & 5 & 2 \\
\hline $\begin{array}{l}\text { Secretaria Municipal de Educação de } \\
\text { Campo Grande }\end{array}$ & --- & 1 & 5 & 3 & 4 & 5 & 3 \\
\hline $\begin{array}{l}\text { Sindicato dos Estabelecimentos de } \\
\text { Ensino- SINEPE/MS }\end{array}$ & 2 & --- & 4 & 1 & 3 & 1 & 0 \\
\hline $\begin{array}{l}\text { Universidade Católica Dom Bosco - } \\
\text { UCDB Campo Grande }\end{array}$ & 2 & 1 & 0 & 3 & 1 & 1 & 2 \\
\hline $\begin{array}{l}\text { Universidade Estadual de Mato Grosso } \\
\text { do Sul-UEMS-Dourados }\end{array}$ & 2 & 1 & 4 & 1 & 2 & 1 & 0 \\
\hline $\begin{array}{l}\text { Universidade Federal de Mato Grosso do } \\
\text { Sul - UFMS, Campo Grande }\end{array}$ & 2 & 2 & 0 & 0 & 1 & 5 & 1 \\
\hline $\begin{array}{l}\text { Universidade Anhanguera-UNIDERP- } \\
\text { Campo Grande }\end{array}$ & 2 & --- & 7 & 0 & 3 & 0 & 0 \\
\hline $\begin{array}{l}\text { Federação dos Trabalhadores em } \\
\text { Educação de MS - FETEMS }\end{array}$ & 2 & 1 & 2 & 0 & 0 & 0 & 0 \\
\hline Secretaria de Estado de Trabalho e & --- & 1 & 0 & 1 & 0 & 0 & 0 \\
\hline
\end{tabular}




\begin{tabular}{|l|c|c|c|c|c|c|c|}
\hline $\begin{array}{l}\text { Assistência Social - SETAS Campo } \\
\text { Grande }\end{array}$ & & & & & & & \\
\hline $\begin{array}{l}\text { Instituto Federal de Educação, Ciência } \\
\text { e Tecnologia - IFMS Campo Grande }\end{array}$ & 2 & --- & 0 & 0 & 0 & 0 & 0 \\
\hline $\begin{array}{l}\text { União dos Dirigentes Municipais de } \\
\text { Educação de MS - UNDIME }\end{array}$ & 2 & --- & 0 & 0 & 0 & 0 & 0 \\
\hline $\begin{array}{l}\text { Universidade Federal da Grande } \\
\text { Dourados - UFGD }\end{array}$ & 2 & --- & 0 & 0 & 0 & 0 & 0 \\
\hline
\end{tabular}

Fonte: FEE-MS

Nota: elaboração própria

Pode-se observar pelo Quadro 1 que, incluindo os colaboradores, a maior parte dos integrantes da comissão pertenciam à SED-MS. Somando-se os representantes e colaboradores da SED, SEMED Campo Grande, CEE-MS e CME de Campo Grande obtemos um total de 26 participantes, maior que a soma de todos os outros participantes (24) pertencentes à Comissão.

A maioria dos integrantes da Comissão, além das reuniões específicas, também participava das plenárias do FEE-MS, por ser representante de suas instituições nesse fórum. No ano de 2014 apenas os representantes da SEDMS, SEMED- Campo Grande, CEE-MS participaram de todas as plenárias. Representantes da UFGD, UNDIME e IFMS Campo Grande, embora sejam membros do FEE-MS, não registraram presença em nenhuma Plenária nesse ano. Cabe destacar que em todas as plenárias do FEE-MS no ano de 2014 , foram abordados temas relacionados à elaboração do PEE-MS 2014-2024.

A Comissão para a Elaboração do Plano Estadual de Educação 20142024 iniciou a organização de suas atividades por meio de um plano de trabalho, que foi apresentado na primeira reunião da Comissão em 24 de abril de 2014, com o objetivo de "Elaborar, de forma participativa e democrática, o Plano Estadual de Educação (PEE), alinhado com as metas e estratégias propostas no Plano Nacional de Educação (PNE)". (COMISSÃO PARA A ELABORAÇÃO DO PLANO ESTADUAL DE EDUCAÇÃO, 2014b).

A Comissão planejou a elaboração do PEE-MS em oito etapas e atuou dando orientações desde a análise situacional até sua aprovação. As etapas já previam os meses de realização, como apresentado na Memória da $1^{a}$ reunião em 24 de abril de 2014: 
$1^{a}$ Ełapa - Elaboração da Análise Situacional de MS e de cada meta - maio e junho;

$2^{a}$ Ełapa - Elaboração de orientações aos municípios que sediarão as oficinas regionais -maio e junho;

$3^{a}$ Ełapa - Elaboração dos Regimentos dos seminários - junho;

$4^{a}$ Ełapa - Elaboração das propostas do Texto-Base do PEE-MS que será discutido nos seminários regionais - junho e julho;

$5^{a}$ Ełapa - Realização dos seminários regionais - julho e agosto;

$6^{a}$ Etapa - Sistematização das propostas oriundas dos seminários regionais - agosto;

$7^{a}$ etapa - Realização do Seminário Estadual - fim de agosto;

$7^{a}$ Etapa - Sistematização das propostas do Seminário Estadual setembro;

$8^{a}$ Ełapa - Elaboração do Projeto de Lei e encaminhamento do PL à Assembleia Legislativa - fim de setembro (COMISSÃO PARA A ELABORAÇÃO DO PLANO ESTADUAL DE EDUCAÇÃO, 2014a).

Para atender o cronograma estabelecido, ainda em abril foram criados grupos de trabalho, organizados em 6 oficinas integradas pelos membros da Comissão Estadual e colaboradores. As oficinas seguiram os eixos estipulados no PNE como Apresentado no Quadro 2, cada um deles contemplando um conjunto de metas.

\section{Quadro 2: Número de representantes por instituições e coordenadores das oficinas por eixo, metas e datas das reuniōes em 2014}

\begin{tabular}{|c|c|c|c|c|c|}
\hline N. & Eixos & Metas & $\begin{array}{l}\mathbf{N}^{\circ} \text { de representantes } \\
\text { por instituiçōes }\end{array}$ & $\begin{array}{c}\text { Representa } \\
\text { ntes das } \\
\text { instituições }\end{array}$ & Reuniōes \\
\hline 1 & $\begin{array}{l}\text { Garantia do } \\
\text { direito à } \\
\text { educação } \\
\text { básica com } \\
\text { qualidade }\end{array}$ & $\begin{array}{l}1,2,3 \\
5,6,7 \\
9,10 \mathrm{e} \\
11\end{array}$ & $\begin{array}{l}\text { 6-SED-MS/ } \\
\text { Coordenadora da } \\
\text { Comissão; } \\
\text { 2-CEE-MS; 1-CEE-MS } \\
\text { 2- SINEPE/MS; } \\
\text { 1-IFMS; 2- UNDIME; }\end{array}$ & $\begin{array}{l}\text { SED- } \\
\text { MS/Coor } \\
\text { denadora; } \\
\text { CEE-MS }\end{array}$ & $\begin{array}{l}08,13,14,15,21 \\
22 \text { e } 29 \text { de maio }\end{array}$ \\
\hline 2 & $\begin{array}{l}\text { Superação das } \\
\text { Desigualdades } \\
\text { à Valorização } \\
\text { das Diferenças }\end{array}$ & 4 e 8 & $\begin{array}{l}\text { 2-SED; 1-FEEMS; } \\
\text { 1-UEMS; 1-UFGD; } \\
\text { 1-UNIDERP; } \\
\text { 1-FEAPAE/SETAS, } \\
\text { 1-UFMS; 1- UCDB. }\end{array}$ & $\begin{array}{l}\text { UEMS } \\
\text { UFMS }\end{array}$ & $\begin{array}{l}07 \text { e } 21 \text { de maio e } \\
04 \text { de junho }\end{array}$ \\
\hline 3 & $\begin{array}{l}\text { Valorização dos } \\
\text { Profissionais da } \\
\text { Educação }\end{array}$ & $\begin{array}{l}15, \quad 16 \\
17 \text { e } 18\end{array}$ & $\begin{array}{l}\text { 1-FEEMS;3-SED; } \\
\text { 1-FETEMS; 1-IFMS, } \\
\text { 1-UNCME; } \\
\text { 1-FETEMS. }\end{array}$ & $\begin{array}{l}\text { FETEMS } \\
\text { UNCME }\end{array}$ & $\begin{array}{l}\text { 08, } 19 \text { e } 29 \text { de } \\
\text { maio; } 4 \text { e } 9 \text { de ju- } \\
\text { nho }\end{array}$ \\
\hline 4 & $\begin{array}{l}\text { Educação } \\
\text { Superior }\end{array}$ & $\begin{array}{l}12,13 \\
\text { e } 14\end{array}$ & $\begin{array}{l}\text { 1-CEE/MS; 2-SED. } \\
\text { 1-UNIDERP; } \\
\text { 1-UCDB; } \\
\text { 1-UFMS;1-FEEMS }\end{array}$ & UFMS & $\begin{array}{l}\text { 08, } 16 \text { e } 30 \text { de } \\
\text { maio; } 06 \text { e } 27 \text { de } \\
\text { junho }\end{array}$ \\
\hline 5 & $\begin{array}{l}\text { Gestão } \\
\text { Democrática }\end{array}$ & 19 & $\begin{array}{l}\text { 1-UEMS; 1-UFGD; } \\
\text { 1-UNCME; } 3 \text { SED; } \\
3 \text { UNAES; }\end{array}$ & UFGD & $\begin{array}{l}08 \text { de maio e } 06 \\
\text { de junho }\end{array}$ \\
\hline
\end{tabular}




\begin{tabular}{|c|c|c|c|c|c|}
\hline & & & $\begin{array}{l}1 \text { Assembleia } \\
\text { Legislativa }\end{array}$ & & \\
\hline 6 & Financiamento & 20 & $\begin{array}{l}\text { 1-Assembleia } \\
\text { Legislativa } \\
\text { 2-UFMS; } \\
\text { 1-CEE-MS } \\
\text { 1-SED }\end{array}$ & CEE-MS & $\begin{array}{l}08,15 \text { e } 29 \text { de } \\
\text { maio }\end{array}$ \\
\hline
\end{tabular}

Fonte: 1- Plano de trabalho de elaboração do plano estadual de educação de Mato Grosso do Sul. 2- Calendário de oficinas. Nota: Elaboração própria

Considerando todos os eixos, foram realizadas 25 reuniões, contando com a participação de representantes de várias instituições, essencialmente públicas. Tal comissão se configurou em uma arena de representação pela qual cada representante traz para a arena de disputa, ideias, concepções, valores e objetivos. Se por um lado fica evidente o número superior de representantes do executivo, por outro temos a presença de sindicatos e universidades. Dos conflitos e consensos nesse espaço resultou o Texto-Base que subsidiou a elaboração do PEE-MS 2014-2024.

As oficinas ocorreram nos meses de maio e junho, seguindo um calendário específico, cada oficina realizou em média três reuniões para tratar das metas sob sua responsabilidade. As discussões nessas oficinas deveriam ainda contemplar as proposições aprovadas no II COEE em 2013 e ao mesmo tempo se alinhar às estratégias do PNE, sem deixar de contemplar as especificidades educacionais do estado. O Texto-Base deveria ainda apresentar uma análise situacional da educação no estado, referente a cada meta, assim como no PNE, considerando-se a necessidade de alinhamento entre os planos, como discutem Nascimento, Grossi Junior e Pereira (2017).

Diante da necessidade da elaboração do texto base, a Comissão também ofereceu orientações básicas para a elaboração do PEE-MS, da seguinte forma:

a) Eleger um coordenador da oficina - dia 8/05;

b) Estabelecer uma agenda de trabalho para a elaboração da Análise Situacional e do Texto-Base - maio, junho e julho;

c) Estudar os cadernos de orientação do MEC e as metas e estratégias do PNE;

d) Realizar análise e reflexão sobre as informações e os dados constantes nos sítios educacionais sugeridos pela SASE/MEC e apresentados na $1^{a}$ reunião da Comissão 
e) Elaborar o relatório sistematizado da Análise Situacional de cada meta;

f) Elaborar o Texto-Base contendo as metas e estratégias do PEE-MS alinhadas às do PNE (COMISSÃO DE ELABORAÇÃO DO PLANO ESTADUAL DE MATO GROSSO DO SUL, 2014a).

Na segunda reunião da Comissão, realizada no dia 22 de maio de 2014, foi aprovada a estruturação do Texto-Base do PEE-MS em Introdução, análise situacional da educação em MS e por fim metas e estratégias. Foi estipulado também o prazo de 30 de junho de 2014, para o envio dos textos elaborados pelas oficinas, para serem trabalhados na Subcomissão de Redação Final do Texto-Base, cujos integrantes foram escolhidos nessa reunião (COMISSÃO DE ELABORAÇÃO DO PLANO ESTADUAL DE MATO GROSSO DO SUL, 2014d, s/d).

Na reunião do dia 22 de maio de 2014, foi apresentada a Subcomissão de Planejamento e Apoio aos Seminários, bem como comunicado da definição dos 10 polos regionais para a realização dos Seminários e suas datas de realização para a discussão do Texto-Base do PEE-MS. Cada polo agrega os municípios de seu entorno e é composto por um número de participante, como apresentado no Quadro 3.

Quadro 3 - Municípios polos, quantidade de município por polo, número de participantes por Polo e data da realização do Seminário no Polo

\begin{tabular}{|c|c|c|c|c|}
\hline$N^{\circ}$ Polo & Município Polo & $\begin{array}{l}\text { Quantidade de } \\
\text { municípios }\end{array}$ & $\begin{array}{l}\text { No }^{\circ} \text { total } \\
\text { Participantes por Polo }\end{array}$ & $\begin{array}{l}\text { Data do } \\
\text { seminário }\end{array}$ \\
\hline Polo 1 & Aquidauana & 07 & 119 & $28 / 08 / 2014$ \\
\hline Polo 2 & Campo Grande & 09 & 153 & $02 / 09 / 2014$ \\
\hline Polo 3 & Costa Rica & 05 & 85 & $26 / 08 / 2014$ \\
\hline Polo 4 & Fátima do Sul & 09 & 153 & $27 / 08 / 2014$ \\
\hline Polo 5 & Jardim & 07 & 119 & $29 / 08 / 2014$ \\
\hline Polo 6 & Naviraí & 09 & 153 & $29 / 08 / 2014$ \\
\hline Polo 7 & Nova Andradina & 09 & 153 & $29 / 08 / 2014$ \\
\hline Polo 8 & Paranaíba & 07 & 119 & $26 / 08 / 2014$ \\
\hline Polo 9 & Ponta Porã & 09 & 153 & $22 / 08 / 2014$ \\
\hline Polo 10 & $\begin{array}{lll}\text { São } & \text { Gabriel do } \\
\text { Oeste } & & \\
\end{array}$ & 08 & 136 & $03 / 09 / 2014$ \\
\hline \multicolumn{2}{|r|}{ TOTAL } & 79 & 1343 & \\
\hline
\end{tabular}

Fonte: Regimento Interno dos Seminários Regionais do PEE-MS (2014-2024)

A elaboração do PEE-MS foi a pauta da plenária do FEE, além de apresentar os polos onde os seminários regionais aconteceriam, ainda 
enfatiza que "Ficou acordado que serão realizados Seminários Livres em cada município ou ainda em grupos de dois ou três municípios, conforme conveniência" (FÓRUM ESTADUAL DE MATO GROSSO DO SUL, 2014b).

Para organizar os Seminários Livres a Comissão para a Elaboração do PEE-MS enviou um Ofício Circular PEE/MS n. 13/2014 aos (às) Secretários (as) de Educação e Comissão responsável pela realização dos Seminários Regionais. No referido Ofício, é solicitado que cada município polo indique um coordenador responsável, bem como a data e local que o Seminário Regional acontecerá. Ainda nesse Ofício, é salientada a importância da realização dos Seminários Livres, feitos em cada cidade e orienta

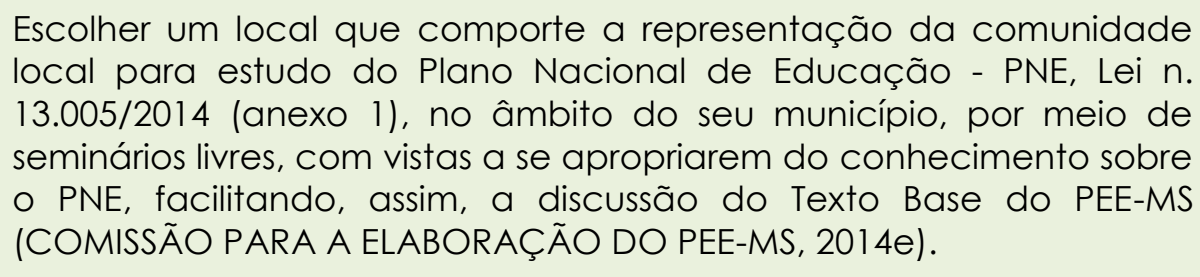

Fica evidente a indução da Comissão para que os municípios se organizem para a realizarem estudos do $\mathrm{PNE}$, o que reafirma o processo educativo implícito à participação, como assinala Gohn (2011, p. 333)

Há um caráter educativo nas práticas que se desenrolam no ato de participar, tanto para os membros da sociedade civil, como para a sociedade mais geral, e também para os órgãos públicos envolvidos - quando há negociações, diálogos ou confrontos (GOHN, 2011, p.333).

É nesse espaço educativo e pedagógico que deve ser feita a escolha dos delegados. Nas instituições participativas, conforme Avritzer (2007, p. 455) "[...] não se representam só discursos, mas também interesses, valores e ideias". Daí a importância dos debates qualificados nos seminários, pois é nesse espaço que são eleitos os delegados, conforme orientação da Comissão. "Nos seminários livres serão escolhidos os delegados do Seminário Regional, com representantes da sociedade civil organizada e movimentos sociais, nos mesmos moldes da realização das conferências ocorridas no ano de 2013" (COMISSÃO DE ELABORAÇÃO DO PEE 2014-2024, 2014e). 
Em 03 de julho de 2014 a Comissão emite mais um Ofício Circular PEE/MS n 16. 2014, com recomendações para as comissões organizadoras dos Seminários Regionais. Nesse ofício, a comissão detalha todas as providências que precisam ser tomadas pela equipe local, dentre elas: seleção de espaço físico com no mínimo seis salas (uma para cada oficina), um computador e projetor para cada sala, um digitador, um coordenador, os delegados eleitos para os seminários regionais deverão tirar cópias do material e fazer a leitura prévia para agilizar o processo, no fim do Seminário Regional serão escolhidos os delegados para participarem do Seminário Estadual. O ofício ainda esclarece que os gastos com o deslocamento dos delegados serão por conta dos municípios e reitera que findados os Seminários Regionais, os polos terão até 05 dias para enviarem o Texto Base do PEE-MS com as contribuições (COMISSÃO DE ELABORAÇÃO DO PEE 20142024, 2014f).

A comissão emite novo Ofício Circular em 7 de agosto de 2014 para orientações dos Seminários Livres, enfatizando a necessidade do estudo dos materiais disponíveis no portal do PEE-MS7. Orienta também que a comissão local deve orientar os interessados em participar do Seminário sobre os procedimentos de inscrição. Ressalta ainda que ao estudar as metas e estratégias do PNE, já podem vislumbrar possibilidades para elaboração do Plano do município que deverá ser elaborado até junho de 2015 (COMISSÃO DE ELABORAÇÃO DO PEE 2014-2024, 2014g).

A Comissão de Elaboração do PEE-MS emitiu 4 Ofícios Circulares. São documentos que evidenciam a necessidade da Comissão em orientar detalhadamente as comissões locais e regionais sobre os procedimentos para realização dos Seminários Livres e Regionais. Além das orientações técnicas, a Comissão enfatizou a importância do estudo do PNE e dos documentos disponíveis no portal do PEE-MS e do FEE-MS, para qualificar a participação.

7http://pee.sistemas.sed.ms.gov.br/Material.aspx

Revista Exitus, Santarém/PA, Vol. 10, p. 01-26, e020040, 2020. 
Nesse sentido, Nogueira (2005, p. 160) afirma que [...] quanto mais participativa é a comunidade, mais procedimentais tendem a ser suas orientações". Isso porque os espaços participativos são permeados por conflitos e precisam ter regras democráticas para que haja a democratização da elaboração de políticas e não seja guiada apenas por princípios tecnocráticos (NOGUEIRA, 2005).

Além dos documentos de orientação, foi oferecida uma capacitação em ambiente virtual aos coordenadores dos seminários regionais e das oficinas. Segundo a Coordenadora da Comissão e representante da SED-MS a intenção é que todos sejam orientados. Para tanto, fazem a seguinte solicitação: "Todos devem ler com antecedência o Plano Nacional de Educação (no portal pee.sistemas.sed.ms.gov.br) e o Manual de Orientações para uso do Sistema nos Seminários Regionais (no endereço http://www.sistemas.sed.ms.gov.br/)" (COMISSÃO PARA A ELABORAÇÃO DO PEE 2014-2024, 2014g). O documento ainda descreve detalhadamente os procedimentos para acesso e participação na formação on line.

A comunicação é um dos elementos basilares da participação, Bordenave (1987) afirma que para haver intervenção das pessoas na tomada de decisão são necessários pelo menos dois elementos comunicativos, a informação e o diálogo. "Não há participação popular sem informação qualitativamente pertinente e quantitativamente abundante" (BORDENAVE, 1987, p. 68).

Nessa direção, Motta (2003, p. 371) ressalta que "Para participar é necessário algum conhecimento e certas habilidades políticas. Isso varia conforme a amplitude da participação e a natureza das matérias em que se participa". Boa parte desses conhecimentos advém das experiências, e é construído participando. Contudo, "[...] participar também implica desejo", pois a participação requer um alto grau de envolvimento, podendo causar desgaste físico e emocional (MOTTA, 2003, p. 371).

As discussões sobre a organização dos seminários regionais foram realizadas nas plenárias do FEEMS, na plenária do dia 30 de julho de 2014 , foram decididos os procedimentos a serem adotados para os Seminários 
Regionais. Nessa ocasião a coordenadora geral do FEEMS leu a minuta do texto base que subsidiará os Seminários e em seguida a minuta do Regimento Interno dos Seminários Regionais e seus anexos, feito alguns ajustes o texto foi aprovado por todos os presentes (FÓRUM ESTADUAL DE EDUCAÇÃO DE MATO GROSSO DO SUL, 2014C).

As discussões nessa plenária do FEE-MS tiveram como pauta exclusivamente assuntos sobre $O$ PEE-MS, mais especificamente a organização dos Seminários Regionais. A aprovação da minuta do texto base e da minuta do Regimento Interno dos referidos Seminários na plenária do FEE-MS evidencia a participação desse Fórum no processo de elaboração do PEE-MS 2014-2024.

Corrobora com essa afirmação a fala da coordenadora do FEE-MS registrada na ata $n^{\circ} 4 / 2014$ do dia 05 de setembro de 2014 , onde ao fazer 0 repasse da reunião ocorrida em Brasília a convite do MEC, enfatizou que "Nessa reunião, foi comentada a pouca participação dos Fóruns Estaduais de Educação na elaboração dos Planos Estaduais de Educação, que não é o caso de Mato Grosso do SUl" (FÓRUM ESTADUAL DE EDUCAÇÃO DE MATO GROSSO DO SUL, 2014d). De fato, em todas as atas de 2014 a pauta principal foi a elaboração do novo PEE-MS.

A ênfase das discussões no FEEMS sobre a realização dos Seminários Regionais se justifica por estes serem a base das discussões para a elaboração do PEE-MS, pois é nesses seminários que ocorrem os debates sobre o texto base, o resultado dessas discussões é que será levado para o Seminário Estadual. $O$ Artigo $3^{\circ}$ do Regimento Interno dos Seminários Regionais, enfatizam essa dinâmica

O Seminário Regional terá caráter deliberativo, devendo discutir as metas e estratégias do PEE-MS constantes do Texto-Base alinhados ao Plano Nacional de Educação (PNE), aprovado pela Lei $10.035 / 2014$, as quais serão encaminhadas para discussão e aprovação no Seminário Estadual (COMISSÃO PARA A ELABORAÇÃO DO PEE 2014-2024, 2014h).

O Regimento Interno do Seminário Regional apresenta em seu Artigo $7^{\circ}$ os detalhes da organização que devem seguir, iniciando com 0 credenciamento dos participantes em seguida a abertura do evento que 
deverá ser presidida pela coordenadora da Comissão de Elaboração do PEE-MS, ou por alguém designado por ela. A palestra de abertura sobre o PEE é opcional e não terá debates ao final. Em seguida será lido o Regimento Interno e será colocado para votação e aprovação (COMISSÃO PARA A ELABORAÇÃO DO PEE 2014-2024, 2014h).

O Regimento Interno dos Seminários Regionais destaca que as plenárias das seis oficinas serão coordenadas por membro da Comissão Organizadora e objetivam discutir e aprovar as metas e estratégias do Texto Base do PEE-MS. O Regimento ainda reserva espaço para a reunião dos segmentos que elegerá os delegados para o Seminário Estadual e será acompanhada ou coordenada por uma pessoa indicada pela Comissão Organizadora (COMISSÃO PARA A ELABORAÇÃO DO PEE 2014-2024, 2014h). Por fim, a plenária final também coordenada por membro da comissão organizadora.

A organização dos seminários regionais foi detalhada em seu Regimento Interno, nele consta a forma da condução das plenárias nas oficinas e plenária final e por fim, orienta que após os seminários, cada polo tem o prazo de 5 dias úteis para envio por endereço eletrônico e via impressa por correio. O tempo curto para o envio das proposições se deve a quantidade de trabalho que a comissão de sistematização terá, pois precisará sistematizar as propostas dos 10 polos elaborando um documento base para o Seminário Estadual.

Além dos Seminários Livres e Regionais, fez parte desse processo a participação das escolas estaduais, denominada "4a etapa da Formação Continuada 2014 - O Plano Estadual de Educação nas Escolas". Esse processo conta com regulamento ${ }^{8}$ específico que orienta as atividades no interior das escolas. O processo, aconteceu de forma semelhante aos Seminários, a comunidade escolar de posse do texto base, se organizavam em 6 oficinas e podiam fazer suas proposições. As proposições desses encontros foram sintetizadas em um único texto.

\footnotetext{
${ }^{8} \mathrm{http} / / /$ pee.sistemas.sed.ms.gov.br/Arquivos/Regulamentos.pdf
} 
Em 5 de setembro a comissão de sistematização já estava trabalhando na adequação do texto base para o Seminário Estadual "O texto base [...] está em processo de sistematização das propostas oriundas dos polos regionais para discussão e aprovação no Seminário Estadual de Educação" (FÓRUM ESTADUAL DE EDUCAÇÃO DE MATO GROSSO DO SUL, 2014d).

Como acordado na plenária do Fórum, e registrado no Regimento Interno (2014), o Seminário Estadual de Educação: Construindo coletivamente o Plano Estadual de Educação (PEE-MS 2014-2024), teve início às $7: 30 \mathrm{~h}$ com o credenciamento dos delegados escolhidos nos seminários regionais, delegados natos e observadores, em quantidade estabelecida pelo anexo II do Regimento e apresentado no Quadro 4.

\section{Quadro 4: Número de delegados por segmentos, para o Seminário Estadual de Educação 2014}

\begin{tabular}{|l|c|}
\hline \multicolumn{1}{|c|}{ Representantes } & $\begin{array}{c}\text { Número de } \\
\text { representantes por } \\
\text { polo }\end{array}$ \\
\hline $\begin{array}{l}\text { Gestores: Diretores/Secretários Municipais de Educação (Educação } \\
\text { Básica e Superior) }\end{array}$ & 4 \\
\hline Profissionais da Educação (Educação Básica e Superior) & 4 \\
\hline Alunos (Educação Básica e Superior) & 4 \\
\hline Pais (Educação Básica) & 2 \\
\hline Povos Indígenas & 2 \\
\hline Movimento negro ou representação quilombola & 2 \\
\hline Movimento social do campo & 2 \\
\hline Educação Especial & 2 \\
\hline Movimento LGBT & 2 \\
\hline Poder Legislativo & 2 \\
\hline Ministério Público & 2 \\
\hline Conselho Municipal de Educação & 2 \\
\hline FETEMS & 2 \\
\hline SINEPE & 2 \\
\hline Total & 34 \\
\hline Total 10 polos & 340 \\
\hline Delegados natos (Comissão Organizadora Estadual e colaboradores) & 50 \\
\hline Observadores & 40 \\
\hline Total geral & 430 \\
\hline Fonte:Regmento InternO do Seminăio Estadual de Educaçă 2014 \\
\hline
\end{tabular}

Fonte: Regimento Interno do Seminário Estadual de Educação 2014

Elaboração: Comissão de Elaboração do PEEMS 2014-2024

A diversidade de segmentos participantes do Seminário é primordial, pois possibilita suas manifestações na elaboração da política tornando-a 
mais abrangente. Nesse sentido Avritzer (2007, p.457) esclarece que "O importante em relação a essa forma de representação é que ela tem sua origem em uma escolha entre atores da sociedade civil, decidida frequentemente no interior de associações civis". Nesse caso específico, nos seminários regionais.

A palestra de abertura teve como tema "Sistema Nacional de Educação, regime de colaboração e Planos de Educação: desafios e articulações necessárias" foi proferida pelo Secretário da SASE - Secretaria de Articulação entre os Sistemas de Ensino do Ministério da Educação.

Depois do intervalo, foi realizada a leitura e aprovação do Regimento Interno, os trabalhos foram encerrados às $12 \mathrm{~h}$. O período vespertino foi destinado às plenárias das 6 oficinas, continuando na manhã no dia 16. A tarde foi realizada a plenária final, com homologação das metas e estratégias do PEE-MS e aprovação do PEE-MS, bem como discussão e aprovação do Projeto de Lei do PEE-MS.

Após o Seminário a equipe de Revisão final realizou a sistematização das propostas e o Projeto de Lei e o PEE-MS, foi encaminhado para a Secretária de Estado de Educação que enviou para a Governadoria. Após essas providências, O PEE-MS foi finalmente encaminhado à Assembleia Legislativa pela Governadoria para apreciação da Comissão de Educação e para aprovação. O PEE-MS (20214-2024) foi aprovado sob a Lei № 4.621, em 22 de dezembro de 2014.

Diante desse cenário, pode-se considerar que o FEE-MS desempenhou papel fundamental na qualificação do processo participativo que envolveu a elaboração do PEE-MS, uma vez que suas orientações perpassam todo o processo de realização dos seminários e conferências realizados nos municípios do estado.

Também se destacam os integrantes do FEE-MS como figuras centrais na comissão de Elaboração do PEE, principalmente aqueles representantes da SED-MS, SEMED- Campo Grande, CEE-MS, que participaram de todas as plenárias. Essa informação, aliada ao fato de que a presidente do FEE-MS era também a presidente do CEE-MS, e servidora da SED-MS, revela uma 
certa fragilidade do processo participativo, uma vez que parece bastante concentrado em representantes institucionais em exercício de cargos e funções junto ao governo do estado.

Tal constatação, no entanto, não invalida o caráter democrático da construção do PEE-MS, haja vista que uma das características das novas democracias, pontuadas por Weffort (1992) é não existência de autonomia plena em relação ao Estado. Considerando principalmente as novas democracias, emergentes após longos períodos ditatoriais, especialmente na América Latina, o autor constata a predominância dos modelos mistos, que se configuram como característica inicial do processo de construção da participação mais amplamente democrática.

Assim, pode-se afirmar que, se por um lado a Comissão para a elaboração do PEE-MS 2014-2024 registra uma relação direta de seus integrantes com o governo do estado, por outro o FEEMS teve papel importante na operacionalização da engenharia participativa e na concretização de uma elaboração coletiva, atuando como um intelectual orgânico no processo.

\section{Considerações Finais}

Os documentos analisados permitem verificar que o Fórum Estadual de Mato Grosso do Sul (FEEMS), se configurou como sujeito determinante no processo de elaboração do Plano Estadual de Educação de Mato Grosso do Sul (PEEMS).

Entre as atividades realizadas pelo FEEMS destacam-se, conforme as atas analisadas: a definição dos polos, orientações para os Seminários Livre e Regionais, definição da data do Seminário Estadual e dos Seminários Regionais, capacitação on line para os coordenadores regionais, definição da metodologia a ser adotada nas oficinas compostas pelos integrantes da Comissão e colaboradores, estudos para elaboração da análise situacional metas e estratégias, sistematização do texto base produzido pelas oficinas, disponibilização do texto base para discussão nos seminários regionais, apresentação do Regimento Interno dos Seminários e seus anexos, 
Sistematização das propostas oriundas dos Seminários Regionais e apresentação na Plenária do FEEMS, apresentação em plenária do FEEMS, da minuta do Regimento Interno a ser aprovado na abertura do Seminário Estadual, ampliação para dois dias para realização do Seminário Estadual, articulação com a UFMS para cessão do espaço para realização do Seminário, realização do Seminário Estadual, sistematização das propostas por comissão de revisão final, encaminhamento para aprovação.

Importa analisar o grau de participação que o Fórum teve no processo de elaboração do PEE-MS 2014-2024. Bordenave (1987) explicita que são questões chaves na participação num grupo ou organização, saber o grau de controle sobre as decisões e quão importantes são as decisões de que se pode participar. Nesse cenário, os registros das atas e da página eletrônica pesquisada evidenciam que não se tratava apenas de comunicar decisões e procedimentos, pelo fato de o Fórum ser um dos integrantes da Comissão. As proposições eram feitas nas plenárias do Fórum e as decisões sobre os rumos da elaboração PEE-MS eram tomadas nesse espaço. O Fórum se constituiu em um espaço de estudos e debates de propostas para o novo PEEMS 2014-2024.

Os Seminários regionais e estadual, assim como as Conferências de educação e a instituição de Fóruns de Educação, nacional, estadual e municipal, cumprem papel de superação histórica "[...] pela lógica da descontinuidade/continuidade, por carência de planejamento de longo prazo e por políticas de governo, em detrimento da construção coletiva, pela sociedade brasileira, de políticas de Estado" (DOURADO, 2014, p. 25).

Nesse sentido, o PEE-MS 2014-2024 é a materialização de um processo que iniciou com as conferências intermunicipais e estadual em 2013 e seminários regionais e estadual em 2014. Esse processo histórico, de conflitos e de consensos, construído por inúmeros sujeitos, com certeza não se encerra com sua legitimação legal, uma vez que o planejamento, enquanto política pública, é uma série histórica de ações e intenções de muitos participantes e não se resume a uma Lei ou projeto (PALUMBO, 1994; VILLANUEVA, 1992). Assim, é preciso que essa engenharia político- 
participativa permaneça nas outras fases dessa política, monitorando e avaliando sua implementação e cumprimento das metas e estratégias estabelecidas.

\section{REFERÊNCIAS}

AVRITZER, L. Sociedade Civil, Instituições Participativas e Representação. Da Autorização à Legitimidade da Ação. Revista de Ciências Sociais, Rio de Janeiro, vol. 50, no 3, p. 443-464. 2007.

BORDENAVE, Juan E. Días. O que é participação. Editora Brasiliense: São Paulo SP. 5 eds. 1987.

BRASIL. Lei $n^{\circ}$ 13.005, de 25 de junho de 2014. Aprova o Plano Nacional de Educação (PNE) e dá outras providências. Presidência da República. Casa Civil. Subchefia para assuntos jurídicos. 2014a. Disponível em: < http://www.planalto.gov.br/ccivil_03/_ato2011-2014/2014/lei/l13005.htm>. Acesso em nov. 2014.

COMISSÃO PARA A ELABORAÇÃO DO PEE 2014-2024. Memória da primeira

reunião. 24 de abril de 2014a. Disponível em: <https://docs.google.com /viewer? $a=v \&$ pid=sites\&srcid=ZGVmYXVsdGRvbWFpbnxm b3J1bWVkdWNtc3 xneDoyZWY5 MDc0NjA1NTgyZGEW>

COMISSÃO PARA A ELABORAÇÃO DO PEE 2014-2024. Plano de trabalho de elaboração do plano estadual de educação de Mato Grosso do Sul. 2014b. Disponível em:

<http://pee.sistemas.sed.ms.gov.br/Arquivos/PlanodeTrabalhodoPEEMS.pdf>. Acesso em: dez 2016.

COMISSÃO PARA A ELABORAÇÃO DO PEE 2014-2024. Calendário de oficinas. 2014c. Disponível em: <http://pee.sistemas.sed.ms.gov.br/Arquivos /Calendario.pdf>. Acesso em: dez 2016.

COMISSÃO PARA A ELABORAÇÃO DO PEE 2014-2024. Memória da segunda reunião. 22 de maio de 2014d. Disponível em: <https://docs.google. $\mathrm{com} /$ viewer? $\mathrm{a}=\mathrm{v} \&$ pid=sites\&srcid=ZGVmYXVsdGRvbWFpbnxm b3J1bWVk dWNtc3xneDo3OGJ mNDhINml4NDEWZTNk>. Acesso em: dez. 2015.

COMISSÃO PARA A ELABORAÇÃO DO PEE 2014-2024. Ofício Circular PEE/MS $n^{\circ} .13$, de 14 de julho de 2014e. Disponível em: < http://pee.sistemas.sed.ms. 
gov.br /Arquivos /oficio_circular\%20pee-ms_n_132014.pdf>. Acesso em: dez. 2015.

COMISSÃO PARA A ELABORAÇÃO DO PEE 2014-2024. Ofício Circular PEE/MS $n^{\circ} 16$, de 30 de julho de 2014f. Disponível em: < http://pee.sistemas.sed. ms.gov.br /Arquivos/oficio_circular_pee_n_16_2014_30_07_3 .pdf>. Acesso em dez. 2015.]

COMISSÃO PARA A ELABORAÇÃO DO PEE 2014-2024. Ofício Circular PEE/MS $n^{\circ} 17$, de 7 de agosto de 2014g. Disponível em:< http://pee.sistemas.sed.ms. gov.br /Arquivos/oficio_circular_pee_ms_n_17_07_08.pdf >. Acesso em: dez. 2015.

COMISSÃO PARA A ELABORAÇÃO DO PEE 2014-2024. Regimento interno dos seminários regionais. 2014h. Disponível em: < http://pee.sistemas.sed.ms. gov.br /Arquivos/regimento_interno_pee-ms(30-07).pdf. Acesso em: dez. 2016.

DOURADO, Luiz Fernandes. Conferência Nacional de Educação e a construção de políticas de Estado. In: FRANÇA, M.; MOMO, M. (Org.)

Processo democrático participativo: construção do PNE. Campinas, SP: Mercado das Letras, 2014.

EVANGELISTA, Olinda. Apontamentos para o trabalho com documentos de política educacional. 2012. Disponível em: <http://pt.scribd.com/doc/ 21 1971320/texto-Olinda-PDF\#scribd>. Acesso em: 04 jan. 2018.

FÓRUM ESTADUAL DE MATO GROSSO DO SUL. Portaria FEEMS $\mathbf{n}^{\circ} \mathbf{7}$, de 7 de dezembro de 2012. Constitui o Grupo de Trabalho Temporário no Fórum Estadual de Educação de Mato Grosso do Sul e dá outras providências. 2012. Disponível em:< https://docs.google.com/viewer?a=v\&pid=sites\&srcid =ZGVmYXVsdGRvbWFpbnxmb 3J1bWVkdWNtc3xneDozMTk3ZWJkOD c3NmY1MjFm>. Acesso em: dez. 2015.

FÓRUM ESTADUAL DE MATO GROSSO DO SUL. Relação dos municípios que implantaram ou estão em fase de implantação do FMEs. 2013a. s/d. Disponível em: <https://sites.google.com/site/forumeducms/system/ app/pages/search?scope=search-ite\&q=Rela\%C3\%A7\%C3\%A3o+dos +munic\%3\%ADpios+que+implantaram+ ou+est\%C3\%A3o+em+fase+de+ implanta\%C3\%A7 \%C3\%A3o+do+FMEs\%2C+nomes+ dos+respons\%C3\%A 1 veis 
+pela+Comiss\%C3\% A3o+Provis\%C3\%B3ria+e+fone\%2Fe-mail+para+contato>. Acesso em: dez.2015

GANZELI, Pedro. Plano Nacional de Educação: implicações para a Educação Infantil. Revista Exitus, Santarém, PA, vol. 02, nº 02, Jul./Dez. 2012. Disponivel em:

http://www.ufopa.edu.br/portaldeperiodicos/index.php/revistaexitus/article/ view/107 Acesso em: jan 2020.

GOHN, Maria da Glória. Movimentos sociais na contemporaneidade. Revista Brasileira de Educação. v. 16 n. 47 maio-ago. 2011 . Disponível em: < http://www.scielo.br/pdf/rbedu/v16n47/v16n47a05.pdf>. Acesso em: dez. 2017.

MOTTA, Fernando C. Prestes. Administração e participação: reflexões para a educação. Educação e Pesquisa, São Paulo, v.29, n.2, p. 369-373, jul./dez. 2003. Disponível em: < http://www.scielo.br/pdf/ep/v29n2/a 14v29n2.pdf>. Acesso em: jul. 2007.

NASCIMENTO, Gilvânia da Conceição; GROSSI JUNIOR, Geraldo, PEREIRA, Jhonata Moreira. Planos municipais de educação - perfil dos municípios que não possuíam plano municipal de educação no segundo ano de vigência da lei n. 13.005/14. Revista Exitus, Santarém, PA, vol. 7, Nº 1, p. 108-130, Jan/Abr 2017. Disponivel em:

http://www.ufopa.edu.br/portaldeperiodicos/index.php/revistaexitus/article/ view/187. Acesso em: jan 2020.

NOGUEIRA, Marco Aurélio. Um Estado para a sociedade civil: temas éticos e políticos da gestão democrática. 2 ed. São Paulo: Cortez, 2005.

PALUMBO, Dennis J. Public Policy in América - Government in Action. 2. ed. Tradução: Adriana Farah. Harcourt Brace \& Company, 1994. p. 8-29.

RICHARDSON, R. J. Pesquisa social: métodos e técnicas. 3. ed. São Paulo: Atlas, 1999.

VILLANUEVA, LUiz, F. Aguilar. La hechura de las políticas. Estudio Introductório y edicion. $1^{a}$ ed. México: Miguel Angel Porrua grupo editorial. 1992. 442p. Colección Antologías de Política Pública. Segunda antologia. Disponível em: < http://www.inap.mx/portal/images/RAP/la\%20hechura\%20de\%20las\% 20politicas.pdf > . Acesso em: out. 2015. 
WEFFOT, Francisco. Novas democracias: que democracias? Lua Nova. 1992. Disponível em:<www.scielo.br/scielo.php?script=sci_arttext\&pid =S010264451992000300002>. Acesso em: dez. 2016

Recebido em: 12 de novembro de 2019 Aprovado em: 06 de maio de 2020 Publicado em: 15 de maio de 2020 